\title{
A single parameter representation of hygroscopic growth and cloud condensation nucleus activity
}

\author{
M. D. Petters and S. M. Kreidenweis \\ Department of Atmospheric Science, Colorado State University, USA \\ Received: 16 August 2006 - Published in Atmos. Chem. Phys. Discuss.: 5 September 2006 \\ Revised: 20 February 2007 - Accepted: 2 April 2007 - Published: 18 April 2007
}

\begin{abstract}
We present a method to describe the relationship between particle dry diameter and cloud condensation nuclei $(\mathrm{CCN})$ activity using a single hygroscopicity parameter $\kappa$. Values of the hygroscopicity parameter are between 0.5 and 1.4 for highly-CCN-active salts such as sodium chloride, between 0.01 and 0.5 for slightly to very hygroscopic organic species, and 0 for nonhygroscopic components. Observations indicate that atmospheric particulate matter is typically characterized by $0.1<\kappa<0.9$. If compositional data are available and if the hygroscopicity parameter of each component is known, a multicomponent hygroscopicity parameter can be computed by weighting component hygroscopicity parameters by their volume fractions in the mixture. In the absence of information on chemical composition, experimental data for complex, multicomponent particles can be fitted to obtain the hygroscopicity parameter. The hygroscopicity parameter can thus also be used to conveniently model the CCN activity of atmospheric particles, including those containing insoluble components. We confirm the applicability of the hygroscopicity parameter and its mixing rule by applying it to published hygroscopic diameter growth factor and $\mathrm{CCN}$-activation data for single- and multi-component particles containing varying amounts of inorganic, organic and surface active compounds. We suggest that $\kappa$ may be fit to CCN data assuming $\sigma_{s / a}=0.072 \mathrm{~J} \mathrm{~m}^{-2}$ and present a table of $\kappa$ derived for this value and $\mathrm{T}=298.15 \mathrm{~K}$. The predicted hygroscopicities for mixtures that contain the surfactant fulvic acid agree within uncertainties with the measured values. It thus appears that this approach is adequate for predicting $\mathrm{CCN}$ activity of mixed particles containing surface active materials, but the generality of this assumption requires further verification.
\end{abstract}

Correspondence to: $\mathrm{M}$. D. Petters

(petters@atmos.colostate.edu)

\section{Introduction}

Simple and accurate descriptions of cloud condensation nucleus $(\mathrm{CCN})$ activity of complex atmospheric aerosols are needed to better constrain cloud resolving models, chemical transport models and global climate simulations (Koch, 2001; Chung and Seinfeld, 2002; Liu et al., 2005). Köhler theory (Köhler, 1936) predicts CCN activity based on the aerosol physicochemical properties, i.e. solute mass, molecular weight, bulk density, dissociable ions, and activity coefficient. Inorganic compounds, which are generally effectively modeled by the parameters and assumptions used in Köhler theory, are ubiquitous in atmospheric particulate matter, but it was recognized some time ago that less- and nonhygroscopic organic compounds can contribute substantially to, and sometimes even dominate, atmospheric aerosol mass concentrations (Kanakidou et al., 2005). Particularly for aerosols that are not sampled close to emissions, it has been found that most particles do not consist of a single component, but rather that organic and inorganic constituents are usually found in the same particles (Murphy et al., 1998).

Early descriptions of internally-mixed particles conceptually decomposed the particle into an insoluble and nonhygroscopic core immersed in an aqueous-ionic solution of some assumed composition, usually sodium chloride or ammonium sulfate (Junge and McLaren, 1971; Fitzgerald, 1973). Although this description sometimes improves comparisons between measured and modeled CCN activity, it cannot explicitly treat the variations in hygroscopic growth attributable to water soluble organic carbon, including constituents originating from biomass burning and secondary organic aerosol formation. This gap was filled by extensions of Köhler theory (Shulman et al., 1996; Kulmala et al., 1997; Laaksonen et al., 1998). However, application of the extended theories requires that the properties of all participating compounds are known. Although this approach has been applied successfully to laboratory data for single-component

Published by Copernicus GmbH on behalf of the European Geosciences Union. 
and some multicomponent particles (Raymond and Pandis, 2002, 2003; Bilde and Svenningsson, 2004; Huff-Hartz et al., 2006; Svenningsson et al., 2006), insufficient data (i.e. molecular weights, dry particle densities, dissociable ions, and water activity coefficients) are available to initialize calculations for ambient aerosols containing a multitude of generally unspeciated organic compounds. Further, results of experiments studying the hygroscopicity or CCN activity of lab-generated or atmospheric particles are often presented in terms of either the critical diameter for activation at a specified water vapor supersaturation (relative humidity, $\mathrm{RH}>100 \%$ ), or the diameter hygroscopic growth factor $(\mathrm{RH}<100 \%)$. Although variations in these parameters qualitatively express the relative hygroscopicity of the tested particles, critical diameters and growth factors themselves are not readily applied quantitatively in modeling studies.

Here we build on previously used simple representations of solute hygroscopicity in Köhler theory. We fit observations to a one-parameter model, where the hygroscopicity parameter, $\kappa$, represents a quantitative measure of aerosol water uptake characteristics and CCN activity. Values of $\kappa$ for specific compounds, or for arbitrary mixtures, can be determined experimentally by fitting $\mathrm{CCN}$ activity or hygroscopic growth factor data. In the following sections we present our proposed model and show how this treatment relates to previously-used parameterizations of hygroscopic growth and CCN activity. We also demonstrate how fitted values of $\kappa$ for individual components may be combined to represent the hygroscopic behavior of multicomponent aerosols of known composition.

\section{Model description}

\section{$2.1 \kappa$-Köhler theory}

The saturation ratio, $S$, over an aqueous solution droplet can be calculated from

$S=a_{w} \exp \left(\frac{4 \sigma_{s / a} M_{w}}{R T \rho_{w} D}\right)$,

where $a_{w}$ is the activity of water in solution, $\rho_{w}$ is the density of water, $M_{w}$ is the molecular weight of water, $\sigma_{s / a}$ is the surface tension of the solution/air interface, $R$ is the universal gas constant, $T$ is temperature, and $D$ is the diameter of the droplet. In our proposed parameterization, the hygroscopicity parameter $\kappa$ is defined through its effect on the water activity of the solution:

$\frac{1}{a_{w}}=1+\kappa \frac{V_{s}}{V_{w}}$,

where $V_{s}$ is the volume of the dry particulate matter and $V_{w}$ is the volume of the water.

For a multicomponent system (multiple solutes + water) at equilibrium, for which the Zdanovskii, Stokes, and Robinson (ZSR) assumption applies, the total volume of the water is the sum of the water contents due to the individual components, i.e. $V_{w}=\sum V_{w i}$, and the individual $V_{w i}$ are obtained for $a_{w i}=a_{w}$. Applying the ZSR assumption and rearranging Eq. (2) for $V_{w}$ gives:

$V_{w}=\frac{a_{w}}{1-a_{w}} \sum_{i} \kappa_{i} V_{s i}$

The total volume of the system (water + solute) is

$V_{T}=\sum_{i} V_{s i}+\sum_{i} V_{w i}=V_{s}+V_{w}$.

Defining the individual (dry) component volume fractions as $\varepsilon_{i}=V_{s i} / V_{s}$ and recognizing that $V_{w}=V_{T}-V_{s}$ Eq. (3) becomes

$V_{T}-V_{s}=\frac{a_{w}}{1-a_{w}} V_{s} \sum_{i} \varepsilon_{i} \kappa_{i}$.

The volumes can be converted to their volume equivalent diameters, $D_{d}^{3}=6 V_{s} / \pi$, where $D_{d}$ is the dry diameter, and $D^{3}=6 V_{T} / \pi$, respectively. Solving Eq. (5) for $a_{w}$ and combining the result with Eq. (1) yields the equation defining " $\kappa$-Köhler theory":

$S(D)=\frac{D^{3}-D_{d}^{3}}{D^{3}-D_{d}^{3}(1-\kappa)} \exp \left(\frac{4 \sigma_{s / a} M_{w}}{R T \rho_{w} D}\right)$,

where the overall value for $\kappa$ is given by the simple mixing rule

$\kappa=\sum_{i} \varepsilon_{i} \kappa_{i}$.

Equation (6) applies over the entire range of relative humidity and solution hygroscopicity. It can thus be used to predict particle water content in the subsaturated $(S<1)$ regime, as well as to predict the conditions for cloud droplet activation. The critical supersaturation $\left(s_{c}\right.$, where $s_{c}=S_{c}-1$ and is usually expressed as a percentage) for a selected dry diameter of a particle having hygroscopicity $\kappa$ is computed from the maximum of the $\kappa$-Köhler curve (Eq. 6). Figure 1 shows the relationship between dry diameter and critical supersaturation for a range of constant $\kappa$ values, computed for $\sigma_{s / a}=0.072 \mathrm{~J} \mathrm{~m}^{-2}$ and $T=298.15 \mathrm{~K}$. As will be shown in the next section, $\kappa \sim 1.4$ is an upper limit for the most hygroscopic species typically found in the atmospheric aerosol (e.g. sodium chloride). Lower values of $\kappa$ then indicate less-hygroscopic, or less $\mathrm{CCN}$-active, behavior, with approximately three orders of magnitude spanning the $s_{c}-D_{d}$ space relevant to the atmosphere. The curves follow the expected Köhler slope of $\sim-3 / 2$ (Seinfeld and Pandis, 1998) when $\log \left(D_{d}\right)$ is plotted on the abscissa and $\log \left(s_{c}\right)$ on the ordinate, for $\kappa>0.2$. As $\kappa$ approaches zero, the particle becomes nonhygroscopic and the slope approaches that expected for an insoluble but wettable particle as predicted by the Kelvin equation, i.e. -1 . This can also be seen mathematically from Eq. (6): for $\kappa=0$, the water activity $a_{w}=1$, representing wetting of the dry particle by a pure water film, and Eq. (6) 
reduces to the so-called Kelvin equation. In the intermediate range $0<\kappa<0.2$ lines of constant $\kappa$ are slightly curved, and have the asymptotic slope of $-3 / 2$ only for large particles. This curvature arises from the non-negligible contribution of the initial dry aerosol volume to the total volume of the droplet when the equilibrium water content is relatively small.

2.2 Relationship to previous parameterizations of hygroscopicity

Calculations of water activity used in Eq. (1) have generally been based on Raoult's law, which states that water activity equals the mole fraction of water in solution. Since the dissociating electrolytes sodium chloride and ammonium sulfate were recognized long ago to be major components of the atmospheric aerosol, Köhler (1936) modified Raoult's Law using a constant dissociation factor to compute the total number of moles of solute in solution. Later McDonald (1953) and Low (1969) introduced more general extensions of Raoult's law that use the van't Hoff factor, $i$, or the molal osmotic coefficient, $\Phi$ :

$a_{w}^{-1}=1+i \frac{M_{w} m_{s}}{M_{s} m_{w}} \approx 1+v \Phi \frac{n_{s}}{n_{w}}$,

where $M_{s}$ is the molecular weight of the solute, $m_{s}\left(n_{s}\right)$ and $m_{w}\left(n_{w}\right)$ are the masses (moles) of solute and water, respectively, and $v$ is the total number of ions per dissociating molecule (see Hänel, 1976; Kreidenweis et al., 2005; Svenningsson et al., 2006, for more discussion of these and related approximations). In some studies, both $i$ and $\Phi$ were allowed to vary with water content such that model predictions and independent observations of water activity were in exact agreement. Junge (1950) introduced the soluble fraction, $\varepsilon$, separating the contributions of soluble and insoluble species to the water activity and total droplet volume. The mass or volume fraction of soluble matter is thus an additional parameter that must be specified for the application of Eq. (8) to atmospheric particles using this conceptual framework.

When this framework was applied to the calculation of the $\mathrm{CCN}$ activity of atmospheric particles, either $i$ or the product $\nu \Phi$ was often assumed constant at the dilute conditions present at activation, and together with molecular weight and density were set equal to values corresponding to observed ionic composition or to a "typical salt". The value of the soluble fraction was adjusted to give agreement with observed data (Junge and McLaren, 1971; Fitzgerald, 1973). This single parameter representation of water activity, with $\varepsilon$ as the adjustable parameter, has also been applied to calculations in the subsaturated regime (Svenningsson et al., 1992, 1994, 1997; Pitchford and McMurry, 1994; Swietlicki et al., 1999; Hämeri et al., 2001; Lehmann et al., 2005; Massling et al., 2005; Mertes et al., 2005). In those studies, $\varepsilon$ is defined conceptually as the volume fraction of a model salt in

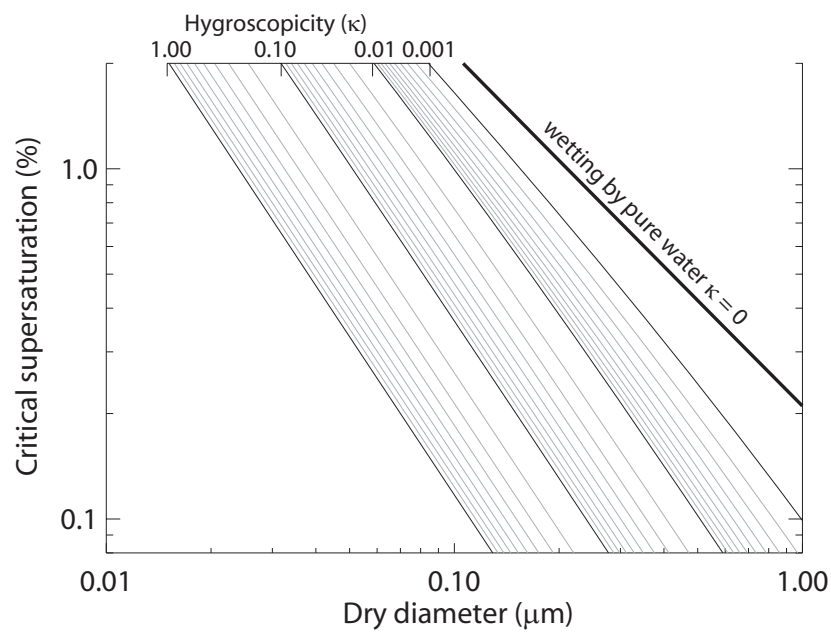

Fig. 1. Calculated critical supersaturation for $0 \leq \kappa \leq 1$ computed for $\sigma_{s / a}=0.072 \mathrm{~J} \mathrm{~m}^{-2}$ and $T=298.15 \mathrm{~K}$. The gray lines are linearly spaced intermediates.

a dry particle consisting of the model salt and an insoluble core, and having the same hygroscopic growth as the actual particle. Applying Eq. (7) to a two-component system of a model salt $\left(\kappa_{m}\right)$ and an insoluble species $(\kappa=0)$ gives $\kappa=\varepsilon \times \kappa_{m}$. Thus, fitting $\varepsilon$ or fitting $\kappa$ are equivalent singleparameter approaches. They fail to be equivalent, however, if $1-\varepsilon$ is interpreted as the actual insoluble fraction in the mixture, since the derived $\varepsilon$ is tied to the choice of the assumed model salt (Rissler et al., 2006).

Equation (2) is equivalent to the mole-fraction-based water activity expressions in Eq. (8), which can be seen by converting moles to volume and gathering all of the compositiondependent variables into the single parameter $\kappa$, here assumed not to vary with particle water content. However, no distinction is made between the soluble and insoluble portions of the dry particle. It is not necessary to do so, as can be seen from the mixing rule discussed in the prior section: the contributions of insoluble species $(\kappa=0)$ can be folded into the average $\kappa$ derived for a particular particle composition. Kappa can then be understood as expressing the volume (or mass or moles, with appropriate unit conversions) of water that is associated with a unit volume of dry particle. This interpretation of $\kappa$ was first pointed out by Rissler et al. (2006), who used a variant of Eq. (2) in their data fitting. Coincidentally, they also denoted their parameter as $\kappa$, although the numerical values are different because of a different choice of units (i.e. their $\kappa$ is defined as the number of soluble moles of ions or non-dissociating molecules per unit volume of dry particle).

A single-parameter fit has also been used to obtain hygroscopicity from $s_{c}-D_{d}$ data (Fitzgerald and Hoppel, 1982; 


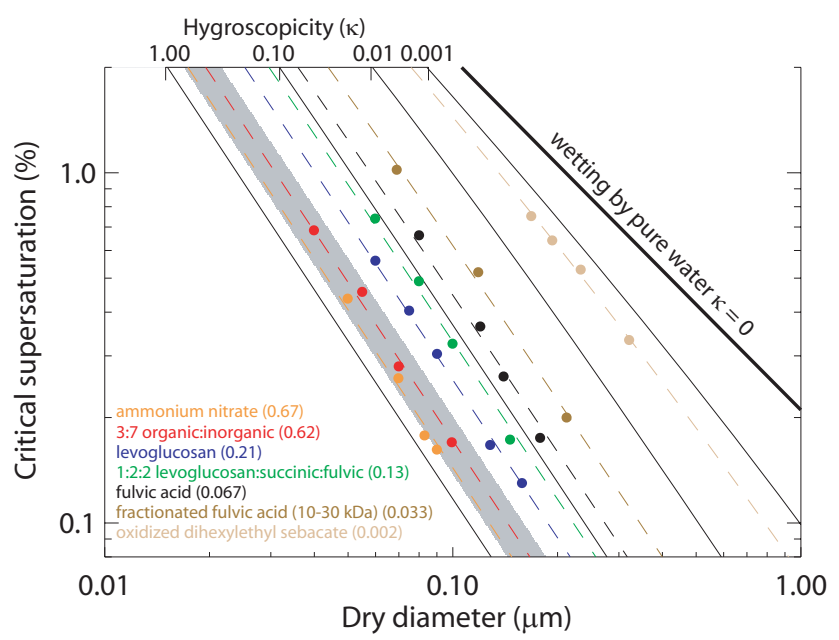

Fig. 2. $s_{c}-D_{d}$ data for pure compounds, organic mixtures and organic-inorganic mixtures. Data are taken from Svenningsson et al. (2006), Dinar et al. (2006), and Petters et al. (2006b). The 3:7 organic:inorganic mixture is the "polluted" mixture from Svenningsson et al. (2006). Dashed lines indicate best-fit $\kappa$ values for each particle type, as shown in the legend. Shaded area indicates reported range of values for ammonium sulfate (Table 1). Kappa values were computed for $\sigma_{s / a}=0.072 \mathrm{~J} \mathrm{~m}^{-2}$ and $T=298.15 \mathrm{~K}$.

Hudson and Da, 1996). The model used was

$s=1+\frac{A}{D}-B \frac{D_{d}^{3}}{D^{3}}$,

where $A$ is essentially a constant at constant temperature (see Eq. 10), and $B$ contains terms relating to solute properties, including the soluble fraction, and serves as the fit parameter. Equation (9) is an approximation to the full equation (Eq. 1 or Eq. 6) that is valid only for $\kappa>0.2$ and $s_{c}<1 \%$. For those conditions, $\kappa$ and $B$ are equivalent parameterizations of CCN activity. Atmospheric particulate matter is typically characterized by $\kappa>0.2$, with lower values sometimes observed for particular locations and periods (Fitzgerald and Hoppel, 1982; Hudson and Da, 1996; Dusek et al., 2006), thereby permitting the use of $B$ in most cases. However, the model represented by Eq. (9) leads to a $-3 / 2$ slope in $\log \left(s_{c}\right)$ $\log \left(D_{d}\right)$ for all choices of $B>0$.

\section{Derivation of $\kappa$ values for atmospherically-relevant species and particle types}

In Fig. 2 we show experimentally-determined critical supersaturations as a function of dry particle diameter for several single- and multi-component particle types, as reported by Svenningsson et al. (2006), Dinar et al. (2006) and Petters et al. (2006b). The data follow, to a good approximation, the slopes of the constant $-\kappa$ lines, and have relative $\kappa$ values as expected: $\kappa$ values for hygroscopic inorganic species (ammonium nitrate) and mixtures containing appreciable amounts of inorganics are close to the $\kappa=1$ line, whereas moderately hygroscopic organic species have CCN activities corresponding to $0.01<\kappa<0.5$. Some chemically aged particles and insoluble particles with trace amounts of hygroscopic inorganic species have $\mathrm{CCN}$ activities corresponding to $0<\kappa<0.01$ (Petters et al., 2006b). Fitzgerald and Hoppel (1982) found ambient values of $0.10<B<0.51$ (computed following Eq. 9, with $B \cong \kappa$ ) for urban, coastal, and marine air masses along the northeastern shore of the United States. Hudson and Da (1996) found $0.1<B<0.94$ for measurements taken at several urban and remote continental sites in the Western United States. The observations of Dusek et al. (2006) for four air masses arriving at Kleiner Feldberg Observatory, and originating over the Atlantic, France, the Ruhr region, and Northern Germany, correspond to values of $0.15<\kappa<0.30$ where $\kappa$ values were calculated from the observed 50\% cutoff diameters reported in their Table 1.

The dashed lines in Fig. 2 indicate best-fit values of $\kappa$, which can be determined by fitting observed values of $s_{c}$ to the maxima of Eq. (6) for the corresponding dry diameter. If $\kappa>0.2$, then $\kappa$ alternatively can be calculated from paired $s_{c}-D_{d}$ values from the following approximate expression:

$$
\begin{gathered}
\kappa=\frac{4 A^{3}}{27 D_{d}^{3} \ln ^{2} S_{c}} . \\
A=\frac{4 \sigma_{s / a} M_{w}}{R T \rho_{w}}
\end{gathered}
$$

Table 1 lists the values of $\kappa$ determined from the data computed for $\sigma_{s / a}=0.072 \mathrm{~J} \mathrm{~m}^{-2}$ and $T=298.15 \mathrm{~K}$, along with best-fit values for several inorganic species. For the inorganic species, except ammonium nitrate, we do not fit $\kappa$ to experimental $\mathrm{CCN}$ values, as these compounds are commonly used for the calibration of $\mathrm{CCN}$ instruments and thus the "experimental" values simply reflect the choice of water activity expression used in the calibration. Instead, a best-fit $\kappa$ is determined from $s_{c}-D_{d}$ relationships computed from Eq. (1), where $a_{w}$ as a function of composition for the aqueous solutions is obtained from the Aerosol Inorganic Model (Clegg et al., 1998). Table 1 also shows the range of $\kappa$ reported for typical experimental uncertainties, for the calibration salts as well as for the other particle types where available.

For a multicomponent particle of known composition, Eq. (7) suggests that the $\kappa$ value expressing its $\mathrm{CCN}$ activity can be estimated from the $\kappa$ values for each constituent. Some limited data on the CCN activity of mixed particles that can be used to test the validity of this mixing rule are available in the literature (Raymond and Pandis, 2003; Broekhuizen et al., 2004; Svenningsson et al., 2006). In Table 1 we list derived $\kappa$ values for individual components, and compare predicted and measured $\kappa$ values in Fig. 3. Mass fractions were converted to volume fractions using bulk density values. Uncertainties in individual component $\kappa$ values were propagated to the prediction in quadrature. An example calculation for a mixed particle is shown in Table 2. In general, the critical supersaturations predicted from Eqs. (6) 
Table 1. Growth factor derived and $\mathrm{CCN}$ derived $\kappa$. Values in the subsaturated domain were derived from growth factors at the highest measured water activity, typically $a_{w} \sim 0.9$. Values in the supersaturated domain were derived from CCN measurements between $0.3 \%$ $<s_{C}<1 \%$, and were computed for $\sigma_{s / a}=0.072 \mathrm{~J} \mathrm{~m}^{-2}$ and $T=298.15 \mathrm{~K}$. Uncertainty calculation varied from study to study and is described in the footnotes. N/A denotes not available.

\begin{tabular}{|c|c|c|c|c|c|c|}
\hline \multirow{2}{*}{ Compound } & \multicolumn{3}{|c|}{ Growth factor derived $\kappa$} & \multicolumn{3}{|c|}{$\mathrm{CCN}$ derived $\kappa$} \\
\hline & $\kappa_{\text {low }}$ & $\kappa_{\text {mean }}$ & $\kappa_{\text {up }}$ & $\kappa_{\text {low }}$ & $\kappa_{\text {mean }}$ & $\kappa_{\text {up }}$ \\
\hline$\left(\mathrm{NH}_{4}\right)_{2} \mathrm{SO}_{4}$ & $0.33^{(6)}$ & 0.53 & $0.72^{(6)}$ & N/A & $0.61^{(13)}$ & N/A \\
\hline $\mathrm{NH}_{4} \mathrm{NO}_{3}$ & N/A & N/A & N/A & 0.577 & $0.67^{(10)}$ & 0.753 \\
\hline $\mathrm{NaCl}$ & $0.91^{(6)}$ & $1.12^{(13)}$ & $1.33^{(6)}$ & N/A & $1.28^{(13)}$ & N/A \\
\hline $\mathrm{H}_{2} \mathrm{SO}_{4}$ & N/A & $1.19^{(13)}$ & N/A & N/A & $0.90^{(13)}$ & N/A \\
\hline $\mathrm{NaNO}_{3}$ & N/A & $0.80^{(13)}$ & N/A & N/A & $0.88^{(13)}$ & N/A \\
\hline $\mathrm{NaHSO}_{4}$ & N/A & $1.01^{(13)}$ & N/A & N/A & $0.91^{(13)}$ & N/A \\
\hline $\mathrm{Na}_{2} \mathrm{SO}_{4}$ & N/A & $0.68^{(13)}$ & N/A & N/A & $0.80^{(13)}$ & N/A \\
\hline$\left(\mathrm{NH}_{4}\right)_{3} \mathrm{H}\left(\mathrm{SO}_{4}\right)_{2}$ & N/A & $0.51^{(13)}$ & N/A & N/A & $0.65^{(13)}$ & N/A \\
\hline malonic acid & 0.28 & $0.44^{(6)}$ & 0.6 & 0.199 & $0.227^{(11)}$ & 0.255 \\
\hline glutaric acid & 0.12 & $0.2^{(6)}$ & 0.28 & $\begin{array}{l}0.054 \\
0.113\end{array}$ & $\begin{array}{l}0.088^{(5)} \\
0.195^{(8)}\end{array}$ & $\begin{array}{l}0.016 \\
0.376\end{array}$ \\
\hline glutamic acid & N/A & $0.154^{(5)}$ & N/A & $\begin{array}{l}0.113 \\
0.158\end{array}$ & $\begin{array}{l}0.182^{(5)} \\
0.248^{(9)}\end{array}$ & $\begin{array}{l}0.319 \\
0.418\end{array}$ \\
\hline succinic acid & N/A & $<0.006^{(12)}$ & N/A & 0.166 & $0.231^{(4)}$ & 0.295 \\
\hline adipic acid & N/A & $<0.006^{(14)}$ & N/A & N/A & $0.096^{(1)}$ & N/A \\
\hline levoglucosan & 0.15 & $0.165^{(6)}$ & 0.18 & 0.193 & $0.208^{(10)}$ & 0.223 \\
\hline phthalic acid & N/A & $0.059^{(5)}$ & N/A & 0.022 & $0.051^{(5)}$ & 0.147 \\
\hline homophthalic acid & N/A & $0.081^{(5)}$ & N/A & 0.048 & $0.094^{(5)}$ & 0.212 \\
\hline leucine & N/A & N/A & N/A & 0.001 & $0.002^{(9)}$ & 0.003 \\
\hline pinic acid & N/A & N/A & N/A & 0.158 & $0.248^{(9)}$ & 0.418 \\
\hline pinonic acid & N/A & $<0.006^{(12)}$ & N/A & 0.063 & $0.106^{(9)}$ & 0.196 \\
\hline norpinic acid & N/A & N/A & N/A & 0.113 & $0.182^{(9)}$ & 0.318 \\
\hline poly(acrylic acid) & N/A & $0.060^{(2)}$ & N/A & 0.040 & $0.051^{(7)}$ & 0.068 \\
\hline Suwanee River fulvic acid & N/A & $\begin{array}{l}0.056^{(2)} \\
0.044^{(12)}\end{array}$ & N/A & $\begin{array}{l}0.057 \\
0.050 \\
0.029\end{array}$ & $\begin{array}{l}0.067^{(10)} \\
0.056^{(3 a)} \\
0.033^{(3 b)}\end{array}$ & $\begin{array}{l}0.077 \\
0.063 \\
0.037\end{array}$ \\
\hline$\alpha$-pinene $/ \mathrm{O}_{3} /$ dark secondary organic aerosol & N/A & $\begin{array}{l}0.022^{(15)} \\
0.070^{(18)} \\
0.037^{(19)}\end{array}$ & N/A & $\begin{array}{l}0.014^{(16)} \\
0.028^{(17)}\end{array}$ & $0.1 \pm 0.04^{(15)}$ & $\begin{array}{l}0.091^{(16)} \\
0.229^{(17)}\end{array}$ \\
\hline$\beta$-pinene $/ \mathrm{O}_{3} /$ dark secondary organic aerosol & N/A & $\begin{array}{l}0.022^{(15)} \\
0.009^{(19)}\end{array}$ & N/A & $\begin{array}{l}0.033^{(16)} \\
0.033^{(17)}\end{array}$ & $0.1 \pm 0.04^{(15)}$ & $\begin{array}{l}0.178^{(16)} \\
0.106^{(17)}\end{array}$ \\
\hline Oxidized diethylhexyl sebacate & N/A & $<0.006^{(20)}$ & N/A & N/A & $0.002^{(20)}$ & N/A \\
\hline
\end{tabular}

${ }^{1}$ Broekhuizen et al. (2004), uncertainty not available; $\kappa$ was calculated for the pure metastable adipic acid data point

${ }^{2}$ Brooks et al. (2004), uncertainty not available

${ }^{3}$ Dinar et al. (2006), uncertainty evaluated from $\pm D_{c}$; a: untreated; b: fractionated $10-30 \mathrm{kDa}$

${ }^{4}$ Hori et al. (2003), uncertainty denotes \pm one standard deviation calculated from spread in the data

${ }^{5}$ Huff Hartz et al. (2006), uncertainty evaluated from $\pm D_{c}$; mass growth factor were converted to size growth factors

${ }^{6}$ Koehler et al. (2006), range of $\kappa$ from Table 3

${ }^{7}$ Petters et al. (2006a), uncertainty evaluated from $\pm s_{C}$

${ }^{8}$ Raymond and Pandis (2002), uncertainty evaluated from $\pm D_{c}$

${ }^{9}$ Raymond and Pandis (2003), uncertainty evaluated from $\pm D_{c}$

${ }^{10}$ Svenningsson et al. (2006), uncertainty denotes \pm one standard deviation calculated from spread in the data

${ }^{11}$ Kumar et al. (2003), uncertainty denotes \pm one standard deviation calculated from spread in the data

${ }^{12}$ Chan and Chan (2003), $\kappa$ estimated from mass growth factors, $g f$ 's for succinic and pinonic acid were below the detection limit

${ }^{13}$ Clegg and Wexler (1998), gf's and $s_{c^{\prime}} s$ calculated from the aerosol inorganic model

${ }^{14}$ Prenni et al. (2003), $g$ f's for adipic acid were below the detection limit

${ }^{15}$ Prenni et al. (2007), uncertainty is $95 \%$ confidence interval with data from $\alpha$-pinene, $\beta$-pinene, $\Delta_{3}$-carene, and toluene precursor lumped into the confidence interval estimate

${ }^{16}$ VanReken et al. (2005), uncertainty denotes minimum and maximum hygroscopicity observed over a five hour experiment. The CCN data did not follow lines of constant $\kappa$.

${ }^{17}$ Huff-Hartz et al. (2005) uncertainty denotes minimum and maximum hygroscopicity observed. The CCN data did not follow lines of constant $\kappa$.

${ }^{18}$ Saathof et al. (2003), data point corresponds to $a_{w}=0.83$ observed $6 \mathrm{~h}$ after introduction of $\alpha$-pinene

${ }^{19}$ Varutbangkul et al. (2006), $180 \mathrm{~nm}$ growth factor data evaluated from fitted parameters at $a_{w}=0.9$ in their Table 5; the hygroscopicity of the ammonium sulfate seed particle was subtracted according to the reported organic volume fraction and using the mixing rule of Eq. (7).

${ }^{20}$ Petters et al. (2006b), all gf's for were below the detection limit 


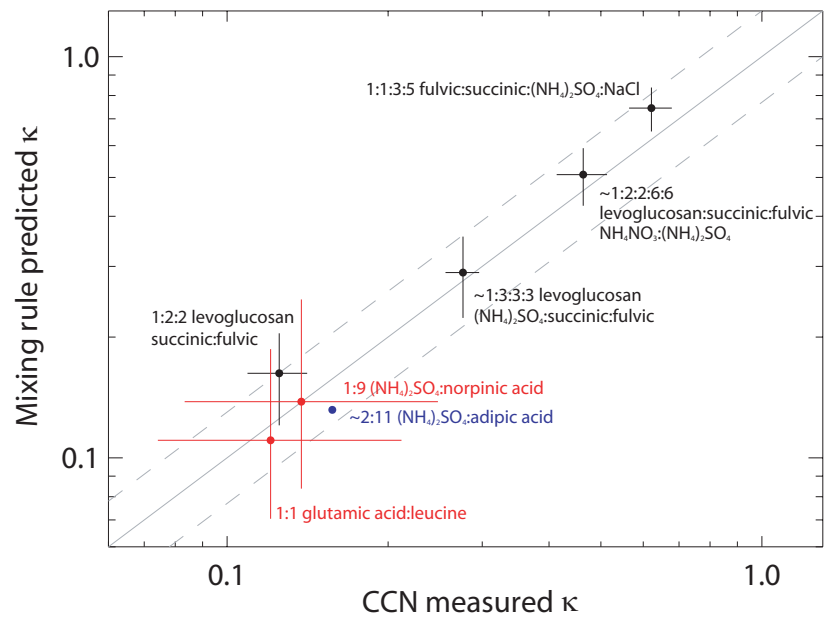

Fig. 3. Values of $\kappa$ for multicomponent particles, predicted from the linear mixing rule (Eq. 7, ordinate) and estimated from CCN activity measurements (abscissa). Measurement-derived $\kappa$ values were fit using $\sigma_{s / a}=0.072 \mathrm{~J} \mathrm{~m}^{-2}$ and $T=298.15 \mathrm{~K}$. Black points: Svenningson et al. (2006); red points: Raymond and Pandis (2003); blue point: Broekhuizen et al. (2004). Indicated component ratios are mass ratios. The value and origin of each individual-component $\kappa$ applied in the mixing rule is given in Table 1. Vertical and horizontal bars show an estimate of the uncertainty in measured and predicted $\kappa$. Dashed lines indicate $\pm 30 \%$ deviation from the 1:1 line. Densities of the pure substances used for the conversion from mass to volume fraction were those reported in the original studies.

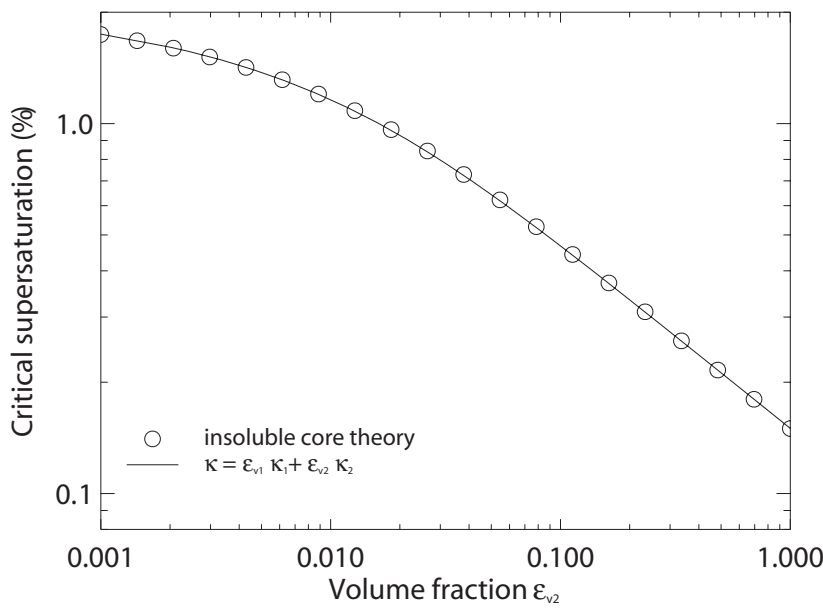

Fig. 4. Calculated critical supersaturations for different values of volume soluble fraction $\varepsilon_{v 2}$ using insoluble core theory (Snider et al., 2003, open symbols) and $\kappa$-Köhler theory (Eqs. 6 and 7 , solid lines). Assumed values are $D_{d}=0.1 \mu \mathrm{m}, \kappa_{1}=0$, $\kappa_{2}=0.615$, corresponding to a nonhygroscopic organic and ammonium sulfate, respectively.

and (7) are within experimental uncertainties, confirming the applicability of the underlying assumptions.

For a multicomponent particle with at least one component having $\kappa=0$, the critical supersaturations predicted by com- bining Eqs. (6) and (7) should be identical to those predicted by a version of Köhler theory that treats insoluble cores immersed in an aqueous ionic solution (e.g. Snider et al., 2003). In Fig. 4 we demonstrate that the supersaturations calculated from Eqs. (6) and (7) for a $0.1 \mu \mathrm{m}$ particle are identical to those predicted by the Snider et al. (2003) formulation.

It must be pointed out that the determination of a value for $\kappa$ from observational data using either Eq. (6) or (10) requires the assumption of a solution surface tension and temperature. In all cases shown here, we have assumed $\sigma_{s / a}=0.072 \mathrm{~J} \mathrm{~m}^{-2}$ and $T=298.15 \mathrm{~K}$. It is now well known that some constituents of the atmospheric aerosol are surface active and can suppress surface tension, sometimes to a significant extent (Facchini et al., 1999; Svenningsson et al., 2006). Use of a lower value of surface tension would result in a decrease in the derived value of $\kappa$. However, this lower $\kappa$ must then be applied in Eq. (6) along with the lower surface tension to correctly predict $s_{c}$. Either approach, as long as $\kappa$ and $\sigma_{s / a}$ are applied self-consistently, should yield estimates of $s_{c}$ that reproduce the data used for the fitting. For example, Fig. 2 suggests that the $\mathrm{CCN}$ activity of fulvic acid, which is known to strongly reduce surface tension in bulk samples (Svenningsson et al., 2006) is parameterized accurately assuming $\sigma_{s / a}=0.072 \mathrm{~J} \mathrm{~m}^{-2}$ and $\kappa=0.067$. In Table 1 we propose a set of $\kappa$ 's that are self-consistent with the $\sigma_{s / a}=0.072 \mathrm{~J} \mathrm{~m}^{-2}$ assumption.

Our initial calculations indicate that this approach may also be adequate, that is, within experimental uncertainties, for estimating $s_{c}$ for mixed particles containing a surface active compound. For example, as discussed earlier, the derived value of $\kappa$ for fulvic acid is biased large since we assumed $\sigma_{s / a}=0.072 \mathrm{~J} \mathrm{~m}^{-2}$. In calculations of $\kappa$ for a mixture containing fulvic acid, the larger $\kappa$ value for this component partially compensates for the lowered surface tension of the mixture. Although this approach is not thermodynamically rigorous, it appears to predict mixed particle hygroscopicity within current measurement uncertainties for mixtures that contain surface active and surface inactive compounds, as is shown in Fig. 3. Furthermore, it is not straightforward to apply measurements of surface tension from bulk solutions to small droplets, where partitioning between the bulk and the surface leads to complicated thermodynamics (Sorjamaa et al., 2004). Also, surface tensions of multicomponent mixtures are not readily predictable, even in bulk solutions (Topping et al., 2005). For these reasons, we believe the use of $\sigma_{s / a}=0.072 \mathrm{~J} \mathrm{~m}^{-2}$ to fit all data represents a reasonable approach to describe hygroscopic behavior of both single components and mixtures, but further testing of this assumption is needed. 
Table 2. Example mixture calculation for the mixture "MIXORG" in Svenningsson et al. (2006). Measured hygroscopicity was $\kappa=0.125 \pm 0.016$ computed for $\sigma_{S / a}=0.072 \mathrm{~J} \mathrm{~m}^{-2}$ and $T=298.15 \mathrm{~K}$. Uncertainty in the prediction was calculated in quadrature. N/A denotes not available. Densities for the pure substances are taken from Svenningsson et al. (2006).

\begin{tabular}{lllll}
\hline Compound & $\kappa \pm \sigma_{\kappa}$ & weight fraction & density $\left(\mathrm{kg} \mathrm{m}^{-3}\right)$ & volume fraction \\
\hline levoglucosan & $0.208 \pm 0.015$ & 0.2 & 1600 & 0.207 \\
succinic acid & $0.231 \pm 0.064$ & 0.4 & 1570 & 0.405 \\
fulvic acid & $0.067 \pm 0.010$ & 0.4 & 1500 & 0.388 \\
\hline$\kappa=\sum \kappa_{i} \varepsilon_{v}$ & $0.163 \pm 0.042$ & 1 & N/A & 1 \\
\hline
\end{tabular}

\section{Links between hygroscopic growth factor and critical supersaturation}

Equation (6) can be used to approximate the size of a particle, characterized by a constant value of $\kappa$, in equilibrium with a specified water vapor saturation for both sub- and supersaturated conditions. In general, however, experimental data for water activities over the full range of solution concentrations cannot be well-fit with Eq. (2) using a constant $\kappa$. For example, Kreidenweis et al. (2005) used a polynomial to model variations in $\kappa$ for $a_{w}<0.95$, and then extrapolated that polynomial to dilute conditions ( $a_{w}$ approaching 1 ) to estimate the critical supersaturation. In that study, water activity data for $\mathrm{RH}<100 \%$ were obtained using a humidified tandem differential mobility analyzer (HTDMA, Brechtel and Kreidenweis, 2000). Extrapolated $s_{c}$ 's using this or similar methods (e.g. Svenningsson et al., 2006) are in good agreement with measured $s_{c}$ 's for many, but not all, particle types studied thus far (Kreidenweis et al., 2005; Koehler et al., 2006; Petters et al., 2006a; Svenningsson et al., 2006). It has been recognized, however, that hygroscopicity is subordinate to particle size with respect to cloud droplet activation properties (Junge and McLaren, 1971; Fitzgerald, 1973; Dusek et al., 2006). Small, and in some cases, moderate variations in $\kappa$ have little to no effect on the fraction of activated droplets, when the activation of a population of particles in a parcel experiencing changing supersaturations is simulated (Ervens et al., 2005; Koehler et al., 2006). Thus, we hypothesize that a constant $\kappa$ is likely sufficient to adequately treat aerosolwater interactions in both the sub- and supersaturated domains, as was done by Svenningsson et al. (1992), who used values of $\varepsilon$ fit to sub-saturated hygroscopicity data to estimate cloud and fog droplet activation. To examine the applicability of the single parameter approach over both the suband super-saturated domains, we derive $\kappa$ either by fitting CCN activity data, as described above, or from HTDMAdetermined values of the hygroscopic diameter growth factor, $g f$, as a function of relative humidity, $\mathrm{RH}$, that have been fit to a rearranged version of Eq. (6):

$\frac{\mathrm{RH}}{\exp \left(\frac{A}{D_{d} g f}\right)}=\frac{g f^{3}-1}{g f^{3}-(1-\kappa)}$, where RH has been expressed as a fraction. The utility of Eq. (2) over Eq. (8) is seen here because wet and dry volume are native variables of the HTDMA method, as opposed to mass or moles which must be computed from volume using assumed or measured molecular weights and densities. In Fig. 5 we compare $\kappa$ values derived from HTDMA data with those derived from $\mathrm{CCN}$ activity measurements, for a variety of particle compositions for which both types of data appeared in the literature (see Table 1 for sources). The agreement is within $30 \%$ for most compounds, indicating that the change in $\kappa$ from $a_{w} \sim 0.9$ to $a_{w}$ at $\mathrm{CCN}$ activation is small. Furthermore, this difference in $\kappa$, although undoubtedly present, appears to not be effectively resolved using current measurement techniques, as can be seen by the sometimes substantial uncertainties in the inferred $\kappa$.

For some of the compounds shown in Table 1, e.g. adipic or succinic acid, no water uptake is observed in the subsaturated domain. The current detection limit for the diameter growth factor measurement is $\sim 1.02$, translating to a lower limit of $\kappa \sim 0.006$ that can be observed in an HTDMA, with a similar limit for the electrodynamic balance. A quick comparison between growth factor derived and $\mathrm{CCN}$ derived $\kappa$ values for these compounds shows, however, that $\kappa<0.006$ does not match the much larger values inferred from their $\mathrm{CCN}$ activity. While the $\mathrm{CCN}$ derived hygroscopicity of succinic and adipic acid is fairly large $(\kappa>0.1$, cf. Table 1$)$, their solubility in water, i.e. the mass of solute that can be dissolved in a given amount of water, is small. Accordingly, the water activity of the saturated solution is large, thereby raising the deliquescence relative humidity, for small particles sometimes exceeding values of $100 \%$. The equilibrium water content of a succinic acid particle at $a_{w} \sim 0.9$ corresponds to a metastable state where the concentration of solute exceeds the solubility limit. Thus, for an initially dry succinic acid particle no water uptake can be observed. In the case of adipic acid the solubility limit is so low that the water activity of the saturated solution exceeds $a_{w}>0.97$. Then $\mathrm{CCN}$ activation will be controlled by the solubility limit instead of its intrinsic hygroscopicity and $s_{c}-D_{d}$ data for these compounds do not observe the $-3 / 2$ rule shown in Fig. 1 (Kreidenweis et al., 2006). Laboratory studies have shown 


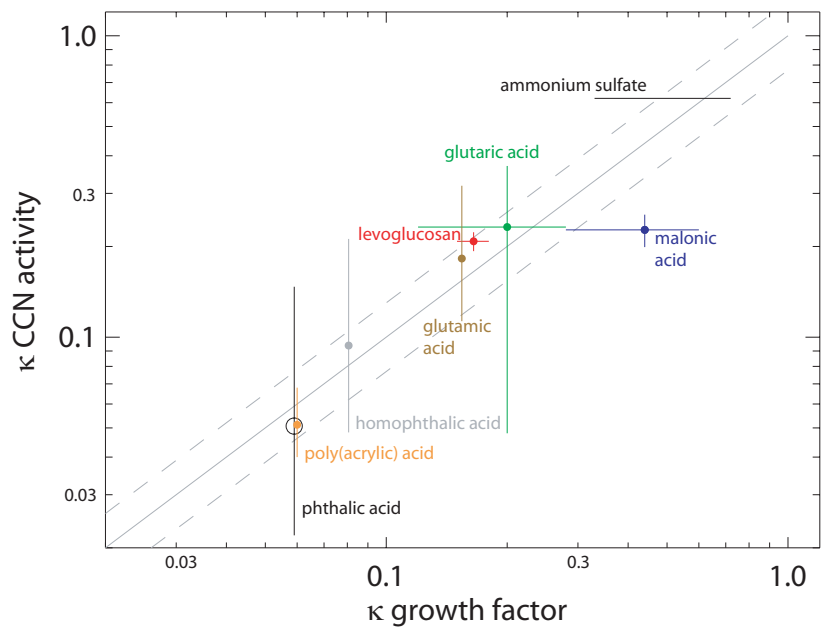

Fig. 5. Values of $\kappa$ for indicated particle types, estimated from $g f$ data and Eq. (11) (abscissa) and estimated from $\mathrm{CCN}$ activity measurements (ordinate). All $\kappa$ values were fit using $\sigma_{s / a}=0.072 \mathrm{~J} \mathrm{~m}^{-2}$ and $T=298.15 \mathrm{~K}$. Data sources are summarized in Table 1. Vertical and horizontal bars show an estimate of the uncertainty in $\kappa$. Dashed lines indicate $\pm 30 \%$ deviation from the $1: 1$ line.

that it is quite difficult to obtain pure, dry compounds for which activation is controlled by the solubility limit, since trace amounts of water or soluble compounds readily lead to metastable solution droplets and hygroscopicity controlled activation (Hori et al., 2003; Bilde and Svenningsson, 2004; Broekhuizen et al., 2004; Huff-Hartz et al., 2006). Although the phase state of aerosols in the atmosphere is not precisely known, it seems reasonable to assume that metastable states dominate, especially because most particles exist as internal mixtures in the atmosphere (Murphy et al., 1998).

\section{Summary and conclusions}

We propose the use of a hygroscopicity parameter, $\kappa$, for purposes of characterizing the relative hygroscopicities of individual aerosol constituents, known mixtures, and complex atmospheric aerosols. The hygroscopicity parameter is used to model the composition-dependence of the solution water activity, and when combined with the Kelvin term into " $\kappa$ Köhler theory", determines the equilibrium water vapor saturation ratio, $S$, over an aqueous droplet. As with traditional Köhler theory, the maximum in $S(D)$ computed for a specified initial dry particle size and composition (expressed by $\kappa)$ determines the particle's critical supersaturation $\left(s_{c}\right)$ for activation to a cloud droplet.

Fits to theoretical $s_{c}-D_{d}$ relationships are used to show that $0.5<\kappa<1.4$ for hygroscopic inorganic species, computed from known solution thermodynamic properties. In contrast, experimental $s_{c}-D_{d}$ data for organic species and their mixtures span a wider range of hygroscopicities and are best fit to lower values of $\kappa, 0.01<\kappa<0.5$. Atmospheric particu- late matter is typically characterized by $0.1<\kappa<0.9$ (Fitzgerald and Hoppel, 1982; Hudson and Da, 1996; Dusek et al., 2006). We use published data to show that the $\kappa$ values describing the hygroscopic behavior of multicomponent particles can be derived by volume-weighting the best-fit $\kappa$ values for the individual constituents. This mixing rule holds even when one or more components are nonhygroscopic $(\kappa=0)$, namely, the equations presented here predict the same critical supersaturations as do extensions of Köhler theory that treat insoluble cores.

We suggest that $\kappa$ may be fit to $\mathrm{CCN}$ data assuming $\sigma_{s / a}=0.072 \mathrm{~J} \mathrm{~m}^{-2}$. Using this convention, the predicted hygroscopicities for mixtures that contain the surfactant fulvic acid agree within uncertainties with the measured values. It thus appears that this approach is adequate for predicting $\mathrm{CCN}$ activity of mixed particles containing surface active materials, but the generality of this assumption requires further verification.

In contrast to traditional formulations of Köhler theory, use of the hygroscopicity parameter to compute $s_{c}$ obviates the need to determine, or assume, aerosol properties such as dry particle density, molecular weight, and dissociation constants. That is, data for the $s_{c}-D_{d}$ relationships observed for model or actual atmospheric aerosols can be conveniently fit by a single parameter. We suggest that $\kappa$ may be useful in streamlining aerosol compositional models, including those that link to drop activation schemes, as well as enable such models to handle the hygroscopic properties of complex aerosol types that were heretofore difficult to fit to traditional Köhler parameters. Representative values of $\kappa$ may be assigned to an aerosol source, e.g. "open flame shrub burning" or "biogenic secondary organic aerosol", or may be computed from concentrations determined from chemical speciation techniques, e.g. functional groups from FTIR (Maria et al., 2003), HOA and OOA from the AMS (Zhang et al., 2005), or various categories from WSOC-NMR (Fuzzi et al., 2001). It must be stressed though, that predictions based on chemical speciation techniques are not experimentally verified to date.

It is also possible to derive values of $\kappa$ from other types of data, such as hygroscopic growth factor data obtained from an HTDMA. We show that values of $\kappa$ derived from published HTDMA data are consistent with those derived by fitting published $\mathrm{CCN}$ activity data, for particles that do not remain dry at the upper limit RH achievable in the HTDMA. The level of agreement for the limited available data is generally within experimental errors and probably within the range of $\delta \kappa$ for which minimal effects on activated drop fractions are observed. However, the resolution in $\kappa$ that is required to address outstanding problems in aerosol indirect effects on climate is not yet well-established, and further research on quantifying acceptable uncertainties in $\kappa$ is needed.

Acknowledgements. This material is based upon work supported by the NOAA Climate Program Office (Atmospheric Composition 
and Climate) and by the National Science Foundation under grant ATM-0436196. We thank B. Svenningsson and E. Swietlicki for their helpful comments on single-variable parameterizations. Any opinions, findings, and conclusions are those of the authors and do not necessarily reflect the views of the National Science Foundation.

Edited by: A. Nenes

\section{References}

Bilde, M. and Svenningsson, B.: CCN activation of slightly soluble organics: the importance of small amounts of inorganic salt and particle phase, Tellus B, 56(2), 128-134, 2004.

Brechtel, F. J. and Kreidenweis, S. M.: Predicting particle critical supersaturation from hygroscopic growth measurements in the humidified TDMA. Part II: Laboratory and ambient studies, J. Atmos. Sci., 57(12), 1872-1887, 2000.

Broekhuizen, K., Kumar, P. P., and Abbatt, J. P. D.: Partially soluble organics as cloud condensation nuclei: Role of trace soluble and surface active species, Geophys. Res. Lett., 31(1), L01107, doi:10.1029/2003GL018203, 2004.

Brooks, S. D., DeMott, P. J., and Kreidenweis, S. M.: Water uptake by particles containing humic materials and mixtures of humic materials with ammonium sulfate, Atmos Environ, 38(13), 1859-1868, 2004.

Chan, M. N. and Chan, C. K.: Hygroscopic properties of two model humic-like substances and their mixtures with inorganics of atmospheric importance, Environ Sci. Technol., 37(22), 5109$5115,2003$.

Chung, S. H. and Seinfeld, J. H.: Global distribution and climate forcing of carbonaceous aerosols, J Geophys Res, 107(D19), D4407, doi:10.1029/2001JD001397, 2002.

Clegg, S. L., Brimblecombe, P., and Wexler, A. S.: Thermodynamic model of the system $\mathrm{H}^{+}-\mathrm{NH}_{4}^{+}-\mathrm{Na}^{+}-\mathrm{SO}_{4}^{2-}-\mathrm{NH}_{3}-\mathrm{Cl}^{-}-\mathrm{H}_{2} \mathrm{O}$ at 298.15 K, J. Phys. Chem. A., 102(12), 2155-2171, 1998.

Dinar, E., Taraniuk, I., Graber, E. R., Katsman, S., Moise, T., Anttila, T., Mentel, T. F., and Rudich, Y.: Cloud Condensation Nuclei properties of model and atmospheric HULIS, Atmos. Chem. Phys., 6, 2465-2481, 2006, http://www.atmos-chem-phys.net/6/2465/2006/.

Dusek, U., Frank, G. P., Hildebrandt, L., Curtius, J., Schneider, J., Walter, S., Chand, D., Drewnick, F., Hings, S., Jung, D., Borrmann, S., and Andreae, M. O.: Size matters more than chemistry for cloud-nucleating ability of aerosol particles, Science, 312(5778), 1375-1378, 2006.

Ervens, B., Feingold, G., and Kreidenweis, S. M.: Influence of water-soluble organic carbon on cloud drop number concentration, J. Geophys. Res., 110(D18), 18211, doi:10.1029/2004JD005634, 2005.

Facchini, M. C., Mircea, M., Fuzzi, S., and Charlson, R. J.: Cloud albedo enhancement by surface-active organic solutes in growing droplets, Nature, 401(6750), 257-259, 1999.

Fitzgerald, J. W.: Dependence of supersaturation spectrum of CCN on aerosol size distribution and composition, J. Atmos. Sci., 30(4), 628-634, 1973.

Fitzgerald, J. W. and Hoppel, W. A.: Measurement of the relationship between the dry size and critical supersaturation of natural aerosol particles, J. Hung. Meteorol. Serv., 86(2-4), 242-248, 1982.
Fuzzi, S., Decesari, S., Facchini, M. C., Matta, E., Mircea, M., and Tagliavini, E.: A simplified model of the water soluble organic component of atmospheric aerosols, Geophys. Res. Lett., 28(21), 4079-4082, 2001.

Hämeri, K., Vakeva, M., Aalto, P. P., Kulmala, M., Swietlicki, E., Zhou, J., Seidl, W., Becker, E., and O'Dowd, C. D.: Hygroscopic and $\mathrm{CCN}$ properties of aerosol particles in boreal forests, Tellus B, 53(4), 359-379, 2001.

Hänel, G.: The properties of atmospheric aerosol particles as a function of relative humidity at thermodynamic equilibrium with the surrounding moist air, Adv. Geophys., 19, 73-188, 1976.

Hori, M., Ohta, S., Murao, N., and Yamagata, S.: Activation capability of water soluble organic substances as CCN, J. Aerosol Sci., 34(4), 419-448, 2003.

Hudson, J. G. and Da, X. Y.: Volatility and size of cloud condensation nuclei, J. Geophys. Res., 101(D2), 4435-4442, 1996.

Huff-Hartz, K. E. H., Rosenorn, T., Ferchak, S. R., Raymond, T. M., Bilde, M., Donahue, N. M., and S. N. Pandis: Cloud condensation nuclei activation of monoterpene and sesquiterpene secondary organic aerosol, J. Geophys. Res., 110(D14), D14208, doi:10.1029/2004JD005754, 2005.

Huff-Hartz, K. E. H., Tischuk, J. E., Chan, M. N., Chan, C. K., Donahue, N. M., and Pandis, S. N.: Cloud condensation nuclei activation of limited solubility organic aerosol, Atmos. Environ., 40(4), 605-617, 2006.

Junge, C.: Das Wachstum der Kondensationskerne mit der relativen Feuchtigkeit, Annalen der Meteorologie, 3, 129-135, 1950.

Junge, C. and McLaren, E.: Relationship of cloud nuclei spectra to aerosol size distribution and composition, J. Atmos. Sci., 28(3), 382-390, 1971.

Kanakidou, M., Seinfeld, J. H., Pandis, S. N., Barnes, I., Dentener, F. J., Facchini, M. C., Van Dingenen, R., Ervens, B., Nenes, A., Nielsen, C. J., Swietlicki, E., Putaud, J. P., Balkanski, Y., Fuzzi, S., Horth, J., Moortgat, G. K., Winterhalter, R., Myhre, C. E. L., Tsigaridis, K., Vignati, E., Stephanou, E. G., and Wilson, J.: Organic aerosol and global climate modelling: a review, Atmos. Chem. Phys., 5, 1053-1123, 2005, http://www.atmos-chem-phys.net/5/1053/2005/.

Koch, D.: Transport and direct radiative forcing of carbonaceous and sulfate aerosols in the GISS GCM, J. Geophys. Res., 106(D17), 20311-20332, 2001.

Koehler, K. A., Kreidenweis, S. M., DeMott, P. J., Prenni, A. J., Carrico, C. M., Ervens, B., and Feingold, G.: Water activity and activation diameters from hygroscopicity data - Part II: Application to organic species, Atmos. Chem. Phys., 6, 795-809, 2006, http://www.atmos-chem-phys.net/6/795/2006/.

Köhler, H.: The nucleus in and the growth of hygroscopic droplets, Trans Farad Soc, 32, 1152-1161, 1936.

Kreidenweis, S. M., Koehler, K., DeMott, P. J., Prenni, A. J., Carrico, C., and Ervens, B.: Water activity and activation diameters from hygroscopicity data - Part I: Theory and application to inorganic salts, Atmos. Chem. Phys., 5, 1357-1370, 2005, http://www.atmos-chem-phys.net/5/1357/2005/.

Kreidenweis, S. M., Petters, M. D., and DeMott, P. J.: Deliquescence-controlled activation of organic aerosols, Geophys. Res. Lett., 33(6), L06801, doi:10.1029/2005GL024863, 2006.

Kulmala, M., Laaksonen, A., Charlson, R. J., and Korhonen, P.: Clouds without supersaturation, Nature, 388(6640), 336-337, 
1997.

Kumar, P. P., Broekhuizen, K., and Abbatt, J. P. D.: Organic acids as cloud condensation nuclei: Laboratory studies of highly soluble and insoluble species, Atmos. Chem. Phys., 3, 509-520, 2003, http://www.atmos-chem-phys.net/3/509/2003/.

Laaksonen, A., Korhonen, P., Kulmala, M., and Charlson, R. J.: Modification of the Köhler equation to include soluble trace gases and slightly soluble substances, J. Atmos. Sci., 55(5), 853862, 1998.

Lehmann, K., Massling, A., Tilgner, A., Mertes, S., Galgon, D., and Wiedensohler, A.: Size-resolved soluble volume fractions of submicrometer particles in air masses of different character, Atmos. Environ., 39(23-24), 4257-4266, 2005.

Liu, X. H., Penner, J. E., and Herzog, M.: Global modeling of aerosol dynamics: Model description, evaluation, and interactions between sulfate and nonsulfate aerosols, J. Geophys. Res., 110(D18), D18206, doi:10.1029/2004JD005674, 2005.

Low, R. D. H.: A generalized equation for the solution effect in droplet growth, J. Atmos. Sci., 26, 608-611, 1969.

Maria, S. F., Russell, L. M., Turpin, B. J., Porcja, R. J., Campos, T. L., Weber, R. J., and Huebert, B. J.: Source signatures of carbon monoxide and organic functional groups in Asian Pacific Regional Aerosol Characterization Experiment (ACE-Asia) submicron aerosol types, J. Geophys. Res., 108(D23), 8637, doi:10.1029/2003JD003703, 2003.

Massling, A., Stock, M., and Wiedensohler, A.: Diurnal, weekly, and seasonal variation of hygroscopic properties of submicrometer urban aerosol particles, Atmos. Environ., 39(21), 3911-3922, 2005.

McDonald, J. E.: Erroneous cloud-physics applications of Raoult's law, J. Meteorol., 10, 68-70, 1953.

Mertes, S., Lehmann, K., Nowak, A., Massling, A., and Wiedensohler, A.: Link between aerosol hygroscopic growth and droplet activation observed for hill-capped clouds at connected flow conditions during FEBUKO, Atmos. Environ, 39(23-24), 42474256, 2005.

Murphy, D. M., Thomson, D. S., and Mahoney, T. M. J.: In situ measurements of organics, meteoritic material, mercury, and other elements in aerosols at 5 to $19 \mathrm{~km}$, Science, 282(5394), 1664-1669, 1998.

Petters, M. D., Kreidenweis, S. M., Snider, J. R. K., Koehler, A., Wang, Q., Prenni, A. J., and DeMott, P. J.: Cloud droplet activation of polymerized organic aerosol, Tellus B, 58(3), 196-205, 2006a.

Petters, M. D., Prenni, A. J., Kreidenweis, S. M., DeMott, P. J., Matsunaga, A. Y., Lim, B., and Ziemann, P. J.: Chemical aging and the hydrophobic-to-hydrophilic conversion of carbonaceous aerosol, Geophys. Res. Lett., 33, L24806, doi:10.1029/2006GL027249, 2006b.

Pitchford, M. L. and McMurry, P. H.: Relationship between Measured Water-Vapor Growth and Chemistry of Atmospheric Aerosol for Grand-Canyon, Arizona, in Winter 1990, Atmos. Environ., 28(5), 827-839, 1994.

Prenni, A. J., DeMott, P. J., and Kreidenweis, S. M.: Water uptake of internally mixed particles containing ammonium sulfate and dicarboxylic acids, Atmos. Environ., 37(30), 4243-4251, 2003.

Prenni, A. J., Petters, M. D., Kreidenweis, S. M., De Mott, P. J., and Ziemann, P. J.: Cloud droplet activation of secondary organic aerosol, J. Geophys. Res., accepted, 2007.
Raymond, T. M. and Pandis, S. N.: Cloud activation of single-component organic aerosol particles, J. Geophys. Res., 107(D24), 4787, doi:10.1029/2002JD002159, 2002.

Raymond, T. M. and Pandis, S. N.: Formation of cloud droplets by multicomponent organic particles, J. Geophys. Res., 108(D15), 4469, doi:10.1029/2003JD003503, 2003.

Rissler, J., Vestin, A., Swietlicki, E., Fisch, G., Zhou, J., Artaxo, P., and Andreae, M. O.: Size distribution and hygroscopic properties of aerosol particles from dry-season biomass burning in Amazonia, Atmos. Chem. Phys., 6, 471-491, 2006, http://www.atmos-chem-phys.net/6/471/2006/.

Saathoff, H., Naumann, K. H., Schnaiter, M., Schock, W., Mohler, O., Schurath, U., Weingartner, E., Gysel, M., and Baltensperger, U.: Coating of soot and $\left(\mathrm{NH}_{4}\right)_{2} \mathrm{SO}_{4}$ particles by ozonolysis products of alpha-pinene, J. Aerosol. Sci., 34(10), 1297-1321, 2003.

Seinfeld, J. H. and Pandis, S. N.: Atmospheric Chemistry and Physics: from air pollution to climate change, John Wiley \& Sons, INC, 1998.

Shulman, M. L., Jacobson, M. C., Carlson, R. J., Synovec, R. E., and Young, T. E.: Dissolution behavior and surface tension effects of organic compounds in nucleating cloud droplets, Geophys. Res. Lett., 23(3), 277-280, 1996.

Snider, J. R., Guibert, S., Brenguier, J. L., and Putaud, J. P.: Aerosol activation in marine stratocumulus clouds: 2. Köhler and parcel theory closure studies, J. Geophys. Res., 108(D15), 8629, doi:10.1029/2002JD002692, 2003.

Sorjamaa, R., Svenningsson, B., Raatikainen, T., Henning, S., Bilde, M., and Laaksonen, A.: The role of surfactants in Kohler theory reconsidered, Atmos. Chem. Phys., 4, 2107-2117, 2004, http://www.atmos-chem-phys.net/4/2107/2004/.

Svenningsson, B., Hansson, H. C., Martinsson, B., Wiedensohler, A., Swietlicki, E., Cederfelt, S. I., Wendisch, M., Bower, K. N., Choularton, T. W., and Colvile, R. N.: Cloud droplet nucleation scavenging in relation to the size and hygroscopic behaviour of aerosol particles, Atmos. Environ., 31(16), 2463-2475, 1997.

Svenningsson, B., Hansson, H. C., Wiedensohler, A., Noone, K., Ogren, J.,Hallberg, A., and Colvile, R.: Hygroscopic Growth of Aerosol-Particles and Its Influence on Nucleation Scavenging inCloud - Experimental Results from Kleiner-Feldberg, J. Atmos. Chem., 19(1-2), 129-152, 1994.

Svenningsson, B., Rissler, J., Swietlicki, E., Mircea, M., Bilde, M., Facchini, M. C., Decesari, S., Fuzzi, S., Zhou, J., Monster, J., and Rosenorn, T.: Hygroscopic growth and critical supersaturations for mixed aerosol particles of inorganic and organic compounds of atmospheric relevance, Atmos. Chem. Phys., 6, 1937-1952, 2006, http://www.atmos-chem-phys.net/6/1937/2006/.

Svenningsson, I. B., Hansson, H. C., Wiedensohler, A., Ogren, J. A., Noone, K. J., and Hallberg, A.: Hygroscopic Growth of Aerosol-Particles in the Po Valley, Tellus B, 44(5), 556-569, 1992.

Swietlicki, E., Zhou, J. C., Berg, O. H., Martinsson, B. G., Frank, G., Cederfelt, S. I., Dusek, U., Berner, A., Birmili, W., Wiedensohler, A., Yuskiewicz, B., and Bower, K. N.: A closure study of sub-micrometer aerosol particle hygroscopic behaviour, Atmos. Res., 50(3-4), 205-240, 1999.

Topping, D. O., McFiggans, G. B., and Coe, H.: A curved multicomponent aerosol hygroscopicity model framework: Part 2 Including organic compounds, Atmos. Chem. Phys., 5, 1223- 
1242, 2005, http://www.atmos-chem-phys.net/5/1223/2005/.

VanReken, T. M., Ng, N. L., Flagan, R. C., and Seinfeld, J. H.: Cloud condensation nucleus activation properties of biogenic secondary organic aerosol, J. Geophys. Res., 110(D7), D07206, doi:10.1029/2004JD005465, 2005.

Varutbangkul, V., Brechtel, F. J., Bahreini, R., Ng, N. L., Keywood, M. D., Kroll, J. H., Flagan, R. C., Seinfeld, J. H. , Lee, A., and Goldstein, A. H.: Hygroscopicity of secondary organic aerosols formed by oxidation of cycloalkenes, monoterpenes, sesquiterpenes, and related compounds, Atmos. Chem. Phys., 6, 23672388, 2006, http://www.atmos-chem-phys.net/6/2367/2006/.
Zhang, Q., Worsnop, D. R., Canagaratna, M. R., and Jimenez, J. L.: Hydrocarbon-like and oxygenated organic aerosols in Pittsburgh: insights into sources and processes of organic aerosols, Atmos. Chem. Phys., 5, 3289-3311, 2005, http://www.atmos-chem-phys.net/5/3289/2005/. 